\title{
MEDIDAS GLOBALES PARA PROBLEMAS GLOBALES
}

\section{GLOBAL SOLUTIONS FOR GLOBAL PROBLEMS}

\section{Nicko Gomero GonzÁLes*}

Docente Asociado de la Facultad de Ciencias Contables, UNMSM

[Recepción: Marzo de 2009 / Conformidad: Mayo de 2009]

\section{RESUMEN}

Los gobiernos vienen implementando medidas fiscales y monetarias más flexibles para revertir los efectos negativos de la crisis global, pero los resultados son estériles o mínimos. A pesar de haberse inyectado miles de millones de dólares en sus operaciones de salvataje financiero, las empresas multinacionales siguen mostrando señales de deterioro económico, tal es así que empresas emblemáticas en el mundo han caído en la peor crisis de su historia. El hecho de que las empresas continúan en el círculo pernicioso de la crisis, a pesar de las ayudas financieras, es valido afirmar que los paradigmas empresariales también necesitan de una reestructuración en lo profundo de su filosofía. Por ello, la crisis que afronta el modelo de globalización no amerita soluciones de coyuntura ya que no serán sostenibles en el tiempo, lo que se requiere son soluciones globales, inclusivas e integradoras de tal forma que lleve a la economía del mundo a desarrollarse simétricamente desterrando para ello todo acción especuladora que como se conoce fue el factor que condujo a la economía mundial a una de las peores crisis de su historia.

Palabras clave: Globalización, crisis financiera, crisis global, inclusión, depresión económica.

\begin{abstract}
Governments are implementing fiscal and monetary flexibility to reverse the negative effects of global crisis, but the results are sterile or minimal. Despite that injected billions of dollars to save their financial operations, multinational corporations continue to show signs of economic deterioration, so much so that flagship companies in the world have fallen into the worst crisis in the history. The fact that businesses continue in the pernicious cycle of crisis; although, financial aid is valid to assert that the paradigms of business also need a deep restructuring of their philosophy. That is why the crisis facing the model of globalization and economic merits of solutions that will not be sustainable over time, which requires global solutions, inclusive and integrate in such a way that leads to the world economy to grow symmetrically banishing all this action is know as speculators which was the factor that led to the global economy to one of the worst crisis of their history.
\end{abstract}

Key words: Globalization, financial crisis, global crisis, including, economic depression.

\footnotetext{
* Doctor en Economía/ E- mail: gomero_econ@yahoo.es
} 


\section{INTRODUCCIÓN}

Los gobiernos continúan percibiendo que las medidas económicas que han implementado para minimizar los impactos de la crisis financiera no están dando los resultados esperados. Las iniciativas de políticas públicas, dentro de ellas los programas rescate financiero sólo se han convertido en vías de entrada de miles de millones de dólares, que en mucho de los casos han ido a parar en las mismas manos de aquellos que originaron la crisis.

Empresas consideradas como emblemáticas del mundo han caído en el peor escenario de crisis de su historia. Las automotrices, bancos, aseguradoras, empresas de aviación, todas ellas multinacionales se han visto forzados a pedir ayuda a sus respectivos gobiernos de lo contrario hubieran salido del mercado. Pero todas estas ayudas financieras que hayan generado efectos positivos en la economía global, definidamente que no, la crisis sigue avanzando y las empresas siguen ajustando sus líneas de producción y costos como últimos recursos para salir de su estado de recesión.

Las medidas económicas han sido improductivas, por ello continúa profundizando las asimetrías entre países, ya que la riqueza global se ha concentrado solo en los países más ricos y se han olvidado de practicar la filosofía social redistributiva. Los países que acumularon mayores riquezas justamente son los que están sufriendo en mayor grado el impacto de la crisis, por ello se dice que en Estados Unidos han aparecido 5.5 millones de desempleados como producto de este fenómeno económico, pero aparentemente no han aprendido la lección ya que creen que esta crisis sólo será coyuntural y que con algunas recetas de tipo keynesiana se romperá el círculo pernicioso de la recesión.
La crisis global necesita de medidas integradoras y de inclusión y no de acciones parciales. Las políticas globales deben estar orientadas a desterrar estructuralmente las asimetrías económicas y sociales, sólo así los efectos tendrán la sostenibilidad que se requiere, con lo cual se evitará caer en un futuro en crisis con mayores efectos perniciosos, lo cual sería catastrófica para la sociedad y las empresas.

Este tema merece una mayor explicación, por ello a continuación se esboza un conjunto de teorías que tratan de explicar por qué la crisis global necesita de soluciones globales.

\section{FUNDAMENTOS DE LOS EFECTOS GLOBALES}

La crisis económica actual, que algunos analistas la han calificado tan igual como la ocurrida en los años de la depresión, ha puesto de manifiesto que el actual modelo económico imperante en el mundo occidental, basado en la filosofía del libre mercado y a veces en los principios doctrinarios del mercantilismo, presenta deficiencias que se tiene que corregir de manera estructural. Con esta afirmación no se pretende decir que hay que voltear la mirada a recetas proteccionistas, tan igual como se aplicó en los años 60 y 70 principalmente en los países que ahora son conocidos como economías emergentes, que por cierto sería una posición extrema que en el largo plazo no conduciría a lograr resultados favorables en las cuentas financieras y sociales de la economía mundial.

Si bien los principios filosóficos del libre mercado y la globalización han conseguido que muchas economías del planeta logren avanzar en su frente externo e interno, tal como es el caso de China, India, Chile y Brasil, sin embargo, este mismo modelo de 
gestión económica ha creado espacios de vulnerabilidad que justamente ahora se ha traducido en crisis global. Las brechas de fragilidad que se han originado en el mundo no sólo es de tipo financiero, sino que existen fenómenos sociales y ambientales muchos más peligrosos, ejemplo de ello es la exclusión y las asimetrías sociales, que de no darse solución en forma integral en el corto o mediano plazo, en un futuro cualquier intento para estabilizar los mercados tenderían a débiles resultados y en el peor de los casos serían totalmente estériles.

Bajo un nuevo modelo de gestión económica no sería suficiente que cada país, especialmente aquellas consideradas las más ricas e industrializadas del mundo, como son Estados Unidos, países de la Zona del Euro y del continente asiático, traten de dar solución a sus problemas unilateralmente. Las políticas públicas que puedan ensayar sus gobiernos respectivos tienen que tener una visión global e integradora y a la vez poseer una alta dosis de contenido social.

Cuando los gobiernos, en especial aquellos que poseen el liderazgo del mundo, mueven una ficha dentro del tablero económico para resolver turbulencias de sus mercados, los efectos de dichas medidas no sólo se focalizarán en su frente interno, sino, dadas las características de la globalización económica, traspasarán sus fronteras, donde se localizan países que al final de cuentas terminan por asumir los costos de la crisis. Bajo este contexto, el escenario económico actual amerita que las políticas de carácter estratégico aparte de ser sincronizadas y coordinar a nivel de las principales economías del mundo deben estar encuadradas bajo la filosofía de la responsabilidad social. El mundo económico actual no requiere de mercantilistas o especuladores que, como bien se conoce, sólo buscan obtener máximos beneficios sin importarles los medios que puedan utilizar para este fin.

Justamente los orígenes de la crisis global, que ha trastocado los cimientos económicos y financieros de muchos países que se consideraban inmunes a fenómenos de esta naturaleza, los podemos encontrar en los movimientos especulativos de entidades financieras, específicamente de bancos de inversión de Estados Unidos como el Lehman Brother, que buscaban obtener las más altas rentabilidades en mercados, como es el inmobiliario, y en su oportunidad habían sido calificado como de alto riesgo. Otro ejemplo, es el caso de la empresa aseguradora más grande del mundo como es la AIG, que para evitar supuestamente el colapso del sistema financiero, el gobierno norteamericano utilizando Fondos del Tesoro se vio en la necesidad de extenderle una línea de crédito por US\$ 170 mil millones, rescatándolo así de una inminente quiebra financiera.

El desarrollo de la ingeniería financiera abrió los espacios para que los especuladores, en su preferencia institucionales, entre ellos los grandes bancos de inversión, busquen alternativas para realizar operaciones especulativas utilizando para tal fin nuevos instrumentos financieros, es así como direccionaron su accionar a mercados donde se negocian derivados y otros tipos de activos financieros, llegando a movilizar capitales especulativos sólo respaldados por contratos pero sin ningún tipo de sustento real o productivo. El objetivo de estos agentes económicos no era la de ejercer palanqueos al escenario productivo, sino lo que buscaban era multiplicar sus niveles de riqueza institucional, sin percatarse de que estos movimientos especulativos estaban carcomiendo las columnas de apoyo de la economía norteamericana.

Al desatarse la crisis, por acciones netamente especulativas, los efectos globales no 
se hicieron esperar, es así como principalmente en la Zona del Euro, se llegaron a presentar graves perturbaciones en el sector productivo y con ello en el mercado financiero y laboral. Caso especial es el de España que fue y sigue siendo el país de destino de peruanos que buscan mejores oportunidades económicas que, por lo sucedido en Norteamérica está experimentando la tasa más alta de desempleo de los últimos 30 años, la cual llega en promedio al $14 \%$, cifra que equivale a más de 3.5 millones de desempleados. Como dicen los analistas económicos, en un mundo globalizado, así como se facilita el flujo del comercio internacional, también es fácil exportar los efectos de la crisis que se desarrollan en una economía local.

Pero los mercados globalizados no iban a permitir que los efectos de la crisis se quede en la Zona del Euro, siguió avanzando a economías asiáticas y latinoamericanas, donde los primeros terminaron por ajustar sus expectativas de crecimientos y los segundos por ser exportadores en su mayoría de materia prima, $y$ en gran medida estar enganchados al avance de las economías desarrolladas, percibieron el lento pero sostenido desaceleramiento de su actividad económica. Así es como el PBI del Perú en febrero del presente año experimentó sólo un crecimiento del $0,18 \%$, resultado que no se observaba desde el año 2000. El mismo caso sucedió con Chile, cuyo debilitamiento de su economía ha comprometido su sector social.

En un mundo globalizado, no existen fronteras cuando se trata de fenómenos económicos y sociales, los errores que se cometen en un país se trasladan inmediatamente a escenarios externos. Los canales de transmisión posibilitan que los efectos se inserten en tres sectores estratégicos como son: el real, financiero y el laboral. La magnitud de los impactos dependerá de su grado de vulnerabilidad ante fenómenos exógenos. En el caso del Perú, las políticas económicas que se implementaron en los últimos años, basado en la disciplina fiscal y monetaria posibilitaron crear ciertas fortalezas que han posibilitado que los efectos de la crisis sean menores con respecto a otros países de la región y el mundo.

Como era de esperarse, los gobiernos afectados por la crisis han diseñado e implementado políticas para salir del entrampamiento económico. Estas medidas se centralizan en una mayor flexibilidad fiscal y monetaria, como la disminución de los tipos de interés, mayor inyección de liquidez, subsidios encubiertos, expansión del gasto público, entre otras medidas expansionistas. Sin embargo, los resultados no han logrado revertir los problemas principales que siguen latentes y que amenazan convertirse en depresión, lo cual sería mucho más peligrosa para la economía mundial. Más claro, las medidas de políticas económicas y públicas calificadas por algunos gobiernos como de emergencia, no han logrado hacer retroceder a la crisis global, por ello, el FMI llegó a establecer que el presente año será de graves dificultades económicas para el mundo.

Dado este escenario y pensando en la viabilidad económica para todas las economías, llamadas emergentes, en desarrollo o industrializadas, es que urge recomponer las políticas públicas que son ejecutadas por los gobiernos, los cuales deben apuntar a fomentar la integración y el crecimiento simétrico de los países.

\section{EMPRESAS Y CRISIS GLOBAL}

Así como existen costos macroeconómicos y macrosociales cuando se desata una crisis, también las empresas se convierten en sujetos de impacto, que dado el caso no le que- 
dará otra opción que salir del mercado. Sin lugar a dudas, las víctimas de las irresponsabilidades económicas, que ahora provienen de la economía más importante del mundo como es Estados Unidos, son los agentes económicos de mayor vulnerabilidad; entre ellas tenemos en especial a las empresas exportadoras que en su debida oportunidad no supieron implementar políticas empresariales de diversificación de mercados. Pero es preciso señalar que el espectro de quiebra no sólo está dirigido a las unidades productivas que se dedican al comercio internacional, sino que el abanico de dificultades empresariales se extenderán cual efecto dominó a todos los sectores y economías que directa $\mathrm{e}$ indirectamente están afectados por la crisis. Aquí nos podemos dar cuenta, cómo la falta de visión global para dirigir los Estados y confiar sólo en la filosofía del libre mercado, genera elevados costos privados y sociales, cuyo proceso de recuperación a veces alcanza el largo plazo.

Como bien se sabe, en un mundo globalizado, un especulador no necesita estar físicamente en un mercado para mover miles de millones de dólares u otro tipo de divisas, las líneas de interconexión posibilita que sus acciones especulativas vayan a la velocidad de la luz simultáneamente en varias plazas financieras, los desequilibrios económicos que pudiera originar estos capitales de corto plazo es segunda o tercera prioridad, lo que interesa es el lucro y la máxima usura que pueda obtener por sus transacciones financieras.

Así como en el actual modelo global económico no existe barreras para las operaciones especulativas que a veces terminan por quebrar a países y gobiernos, los efectos de la crisis tampoco tiene límites y se pueden controlar poniendo barreras de contención, estos se transmiten rápidamente por las principales líneas de contagio que permite la globalización de los mercados. Es así como las empresas comienzan a caer tocadas por el virus de la crisis. Primero bajan sus ventas, las pérdidas de convierten en insostenibles, como no tiene el privilegio de ser rescatados por el gobierno, tiene que salir del mercado, perdiéndose con ello con ello miles o millones de puestos de trabajo.

Aquí algunos datos sobre los efectos de la crisis global sobre las empresas globales:

- General Motors necesitará aumentar su préstamo hasta los 30 mil millones de dólares con el fin de evitar su bancarrota, 12 mil millones más de los que había previsto inicialmente. Además, GM ha asegurado que tiene previsto recortar 47 mil puestos de trabajo antes de que finalice este año — de un total de 244 mil personas que trabajan para la compañía en todo el mundo-. Casi la mitad de estos nuevos despidos, se producirán en EE. UU. El plan también estima que para el 2012 General Motors reducirá sus plantas de producción en Estados Unidos a un total de 33, cinco menos que lo establecido por la empresa en diciembre.

- Las principales empresas automotrices de Estados Unidos reportaron una nueva y fuerte caída en sus ventas de marzo del 2009, lo que contrastaba con las tímidas señales de recuperación en Europa. La oferta de Ford, General Motors, Chrysler y Toyota correspondientes a marzo, se fue en picada entre 39 y 45 por ciento. Ford sufrió en 2008 una pérdida récord de 14 mil 700 millones de dólares. La pérdidas de GM en el 2008 llegó a US\$ 30.900 millones, que se sumaron a los más de US\$ 43.000 millones registrados en el 2007. ${ }^{1}$

1 www.cronistas.com 
- El transporte aéreo profundizó su caída en enero, tanto en el sector de carga como en el de transporte de pasajeros, indicó hoy la Asociación Internacional de Transporte Aéreo (IATA). Según esta entidad internacional, la caída del traslado de cargas fue del $23,2 \%$ en enero, y bajó un 5,6\% la cantidad de pasajeros; "Aún no hemos tocado fondo", dijo el presidente de IATA. ${ }^{2}$

- La aseguradora estadounidense AIG sufrió pérdidas récord de 24.470 millones de dólares (18.946 millones de euros) en el tercer trimestre del año 2008, frente al beneficio neto de 3.090 millones de euros (2.392 millones de euros) del mismo periodo de 2007. Asimismo, la Reserva Federal de EE. UU. (Fed) anunció una reestructuración en el préstamo de rescate de la entidad, que ahora percibirá unos 150.000 millones de dólares (116.130 millones de euros), frente a los 85.000 millones de dólares iniciales (65.807 millones de euros). ${ }^{3}$

- Los beneficios totales de Merrill ajustados a la inflación entre 1971 y 2006 ascendieron a 56.000 millones de dólares. Los 14.000 millones de dólares de pérdidas registrados entre 2007 y los dos primeros trimestres de 2008 equivalen a la mitad de los beneficios totales de Merrill desde principios de esta década. ${ }^{4}$

- El gigante bancario estadounidense Citigroup, en el primer trimestre de 2009, registró pérdidas netas por 966 millones de dólares. En el mismo periodo de 2008, las pérdidas del grupo bancario, actualmente seminacionalizado, aún llegaban a 5.1 mil millones de dólares. Citigroup, una de las instituciones crediticias más golpeadas por la crisis financiera, encadena seis trimestres consecutivos de pérdidas. En 2008 había registrado pérdidas por la cifra récord de casi 28.000 millones de dólares. En tres acciones de rescate emprendidas hasta el momento por el Estado norteamericano, el que fuera el mayor grupo financiero del mundo ha recibido ayudas y garantías por un monto total de casi 350.000 millones de dólares. ${ }^{5}$

- UBS es el banco más importante de Suiza y también es la entidad financiera europea más afectada por la crisis de los 'subprime'. Perdió 2.0 mil millones de francos suizos durante el primer trimestre del 2009. En el 2008 registro pérdidas por 20.000 millones de francos suizos en $2008{ }^{6}$

- El gobierno de Sarkozy prestará 6.000 millones de euros a las empresas PSA Peugeot, Citröen y Renault, en un nuevo rescate al sector automotriz. PSA Peugeot, Citröen y Renault recibirán 3.000 millones de euros (3.900 millones de dólares) cada una, a tasas de interés muy por debajo de los del mercado. A cambio de este préstamo, las dos compañías se comprometen a no cerrar ninguna de sus plantas en Francia ni en el extranjero durante los cinco años que dura el periodo del préstamo.

Como en el mundo occidental las empresas continúan saliendo del mercado y otras siguen profundizando su situación de insolvencia, por cierto en Perú todavía no se

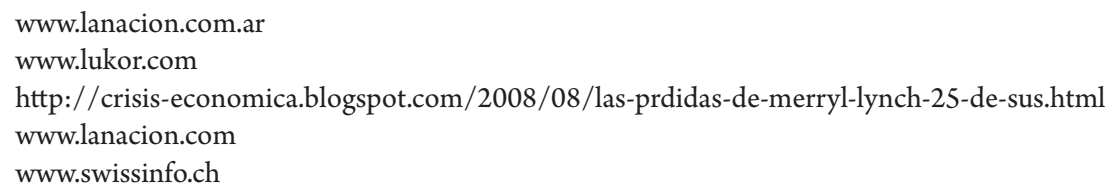


presenta con fuerza este fenómeno económico, El Centro de Estudios Financieros (CEF) ${ }^{7}$ de España, publicó un decálogo de consejos dirigidos a las empresas para afrontar la actual situación de crisis, los cuales se resumen en los siguientes puntos:

1. Negar el impacto de la crisis: Incluso en el caso de empresas que aparentemente todavía no se han visto afectadas por la crisis, y aunque sólo sea en aspectos parciales, la crisis acabará afectando a casi todas las compañías del país.

2. No extremar la cautela: Las empresas no deben descuidar ni sus ingresos, ni sus gastos. Es importante seguir muy de cerca la evolución del mercado y de las ventas.

3. No descuidar la comunicación: El silencio total puede ser tan negativo como una indiscriminada emisión de información.

4. No ponderar los costes e ingresos para cada escenario: Se han de diseñar distintas categorías de posibles acciones, replanteando los objetivos para intentar minimizar las posibles consecuencias negativas de la crisis.

5. 'Pasar' de los presupuestos y del endeudamiento: Es preciso ajustar la cuenta de resultados prevista sobre los gastos de la empresa. La existencia de pérdidas, en particular en el caso de las multinacionales, aumenta el peligro de cierre empresarial.

6. Descuidar la delegación de decisiones: Frente a la incertidumbre reinante, muchas decisiones anteriormente delegadas o automatizadas, deben ser examinadas y, quizás, recentralizadas de nuevo.

7. Continuar 'sin más' los proyectos e inversiones en curso: Es preciso reconsiderar los proyectos en marcha o previstos, manteniendo en el congelador aquellos que no vayan a mejorar a corto plazo los resultados o la facturación.

8. Desatender los posibles cambios del mercado: Cuanto más rápida sea la respuesta de la empresa frente a los cambios del mercado, mejor se podrán planificar las estrategias que permitan restablecer el negocio.

9. Sobre reaccionar: Vivimos una situación delicada, por lo que no se deben tomar decisiones apresuradas. Se debe imponer la templanza.

10. No prever los posibles escenarios una vez superada la crisis: Existe un después de la crisis y hay que pensar en él.

\section{MEDIDAS GLOBALES PARAEVITAR QUIEBRAS GLOBALES}

El espíritu filosófico de las medidas que se han de implementar por iniciativa del G-20 cuya última reunión fue el 2 de abril del presente año se centra en dos de sus primeras conclusiones los cuales se señalan a continuación: ${ }^{8}$

- Primero: Nos enfrentamos al mayor reto para la economía mundial de la era contemporánea; una crisis que se ha agravado desde que nos reunimos la última vez, que afecta a la vida de las mujeres, hombres y niños de todos los países y todos los países deben aunar esfuerzos para resolverla. Una crisis global exige una solución global.

- Segundo: Partimos de la creencia de que la prosperidad es indivisible; de que el crecimiento, para que sea constante, tiene que ser compartido; $y$ de que nuestro plan global para la recuperación debe centrarse en las necesidades y los puestos de trabajo de las familias que trabajan con ahínco, no sólo en los países desarrollados, sino también en los

7 http://www.noticiasdot.com

8 www.elpais.com: 03/04/2009. 
mercados incipientes y en los países más pobres del mundo; $y$ debe reflejar los intereses no sólo de la población actual, sino también de las generaciones futuras. Creemos que el único cimiento sólido para una globalización sostenible y una prosperidad creciente para todos es una economía mundial abierta basada en los principios de mercado, en una regulación eficaz y en instituciones globales fuertes.

- Tercero. Por tanto, hoy nos hemos comprometido a hacer lo que sea necesario para: restablecer la confianza, el crecimiento y el empleo; reparar el sistema financiero para restaurar el crédito; reforzar la regulación financiera para reconstruir la confianza; financiar y reformar nuestras instituciones financieras internacionales para superar esta crisis y evitar crisis futuras; fomentar el comercio y la inversión globales y rechazar el proteccionismo para apuntalar la prosperidad; y construir una recuperación inclusiva, ecológica y sostenible.

Sin lugar a dudas, el actual modelo de globalización atraviesa por su primera crisis. $\mathrm{Si}$ bien en los años 30, que fue el año de la gran depresión, la economía también enfrentó un serio revés productivo, con la quiebra en serie de empresas y la aparición de ejércitos de desempleados, pero el entorno en esos años fue distinto a lo que se presenta actualmente, por ello las recetas de solución al estilo keynesiano sólo se centró en la dinamización de la demanda agregada.

Pero la actual coyuntura es solamente distinta, si bien el mundo ha avanzado a pasos agigantados en todas las ramas económicas, sociales, tecnológicas científicas, entre otros campos, el desarrollo, como bien lo han reconocido los miembros del G-20, no ha sido lo más equilibrado posible- La generación de riqueza no se enmarcó en el principio de la redistribución, por ello las cifras económicas, financieras y sociales señalan la profundización de las asimetrías no sólo entre personas sino también entre países. Algunos de ellos todavía siguen supeditados al desarrollo de sus industrias de materias primas tan igual como se observaba hace 50 años atrás.

Algo paradójico y que demuestra la simetría entre países, son los rescates financieros a las entidades financieras que realizó el gobierno norteamericano. A la AIG le extendió una línea de crédito por US\$170 mil millones, cifra casi igual al PBI de Perú y equivale a cinco veces sus exportaciones. A nivel mundial ha generado que millones de personas vivan con menos de un dólar diario.

A la luz de estas cifras sería inmanejable e insostenible pretender dar solución a la crisis con medidas parciales donde sólo prime los salvatajes financieros a los bancos o las grandes corporaciones transnacionales. Lo que se requiere es emprender grandes proyectos globales de inclusión, sustentados en la filosofía redistributiva de la riqueza global.

Las políticas fiscales, monetarias, de comercio internacional, cambiarias, las públicas en general no sólo deben estar diseñadas para equilibrar mercados locales, situación que quizás se logre en el corto plazo, pero que carecería de sostenibilidad en el tiempo, ya que dadas las características de la globalización, las medidas que implemente un país repercutirá en escenarios económicos externos, que de ser perniciosas ejercerían presiones negativas en el ambiente empresarial.

\section{CONCLUSIONES}

El modelo de globalización enfrenta su primera crisis global, por lo que los efectos perniciosos que ha generado en ámbitos de gobiernos, 
empresas y personas, requiere soluciones globales e integradoras y de tipo estructural. Las medidas de coyuntura sólo podrían tener resultados positivos en el corto plazo pero no tendrían sostenibilidad en el tiempo.

Los gobiernos de Estados Unidos como los de la Zona del Euro han flexibilizado sus políticas económicas, como son las monetarias y fiscales, pero estas medidas como no han dado los resultados esperados, los mercados siguen mostrando señales de debilidad. Este tipo de medidas podría ser un buen ejemplo de por qué la economía global no reacciona ante acciones parciales y de tipo coyuntural.

Las empresas globales son las que vienen experimentando los mayores impactos de la crisis financiera, situación que ha obligado a que los gobiernos participen en su rescate financiero, pero este tipo de medidas no han conducido a revertir los efectos de este fenómeno económico, ya que este tipo de soluciones no están enmarcados bajo el marco filosófico "la crisis global requiere soluciones globales”.
Las asimetrías económicas y sociales entre países se han profundizando con la globalización, situación que se ha profundizado con la crisis global, estas brechas no se han de solucionar con políticas públicas unilaterales, lo que se requiere es que el nuevo modelo económico debidamente reformulado sea aplicado bajo el principio redistributivo y no de la exclusión.

\section{REFERENCIAS BIBLIOGRÁFICAS}

1. http://www.noticiasdot.com

2. www.lukor.com

3. http://crisis-economica.blogspot. com/2008/08/las-prdidas-de-merryllynch-25-de-sus.html

4. www.lanacion.com

5. www.swissinfo.ch 